${ }^{10}$ Astrup P. Some physiological and pathological effects of moderate carbon monoxide exposure. $\mathrm{Br}$ Med $\mathcal{F}$ 1972; iv:447-52.

11 Mitchell JRA, Schwartz CJ. Arterial disease. Oxford: Blackwell Scientific, 1965.

12 Wald NJ, Howard S, Smith PG, Kjeldsen K. Association between atherosclerotic diseases and carboxyhaemoglobin levels in tobacco smokers. Br Med f 1973; :761-5.

${ }^{13}$ Anderson EW, Alderman RJ, Strauch JM, Fortuin NJ, Knelson JH. Effect of low level CO exposure on onset and duration of angina pectoris. Ann Intern Med 1979;79:46-50.

14 Smith JR, Landaw SA. Smokers polycythaemia. N Engl f Med 1978; 298:6-10.

15 Wagner JA, Horvath SM, Andrew GM, et al. Hypoxia, smoking history and exercise. Aviat Space Environ Med 1978;49:785-91.

${ }^{16}$ Kaufman DW, Helmrich SP, Rosenberg L, Miettinen OS, Shapiro S. Nicotine and carbon monoxide content of cigarette smoke and the risk of myocardial infarction in young men. $N$ Engl 7 Med 1983;308: 409-13.

17 Young JC, Robinson JC, Rickert WS. How good are the numbers for cigarette tar at predicting deliveries of carbon monoxide, hydrogen cyanide, and acrolein ? F Toxicol Environ Health 1981; 7:801-8.

is Kensler CJ, Battista S. Chemical and physical factors affecting mammalian ciliary activity. Am Rev Respir Dis 1966;93:93-102.

19 Hoffman D, Wynder EL. A study of tobacco carcinogenesis XI tumour indicators, tumour accelerators and tumour promoting activity of condensate factors. Cancer $1971 ; 27$ (4):848-64.

20 Wald NJ, Boreham J, Bailey A. Risk of myocardial infarction in relation to nicotine and carbon monoxide yields of cigarettes. Thorax (in press)

$\because 1$ Burgess JH. Pulmonary diffusing capacity (for carbon monoxide) in disorders of the pulmonary circulation. Circulation 1974;49:541 50.

(Accepted 8 November 1983)

\title{
Chronic otitis media with effusion (glue ear) and adenotonsillectomy: prospective randomised controlled study
}

\author{
A RICHARD MAW
}

\begin{abstract}
A prospective study was conducted of the effects of adenoidectomy and adenotonsillectomy on established otitis media with effusion unresponsive to medical treatment. The operations were performed at random with a controlled no surgery group on a cohort of 103 children with the condition and the results assessed six weeks, three months, six months, nine months, and one year later. After adenoidectomy the rate of resolution of the condition increased from $39 \%$ at six weeks to $72 \%$ at one year; and after adenotonsillectomy the rate increased from $59 \%$ at six weeks to $62 \%$ at one year. In the no surgery group the rate increased from $16 \%$ at six weeks to $26 \%$ at one year. Compared with the no surgery group the effect of adenoidectomy alone at one year was highly significant $(p<0.001)$, and similarly the effect of adenotonsillectomy was significant $(p<0.01)$. There was, however, no increased benefit from the addition of tonsillectomy compared with adenoidectomy alone. Thus there was resolution of $36-46 \%$ of chronic effusions as a result of adenoidectomy.
\end{abstract}

\section{Introduction}

Otitis media with effusion, a term synonymous with chronic non-suppurative otitis media, secretory otitis media, serous otitis media, and glue ear, is one of the commonest chronic otological conditions of childhood. It results from alteration of the mucociliary system within the middle ear cleft and is frequently caused by malfunction of the eustachian tube. Serous or mucoid fluid accumulates within the cleft where there is a negative pres-

Bristol Royal Infirmary, Bristol BS2 8HW

A RICHARD MAW, MB, FRCs, consultant otolaryngologist sure. It is especially prevalent in children with cleft palate and frequently occurs in association with upper respiratory tract infection and generalised disorders such as allergic rhinitis, fibrocystic disease, and ultrastructural cilial abnormalities of the mucosa of the respiratory tract. The condition presents in children as hearing loss, which may be overt or covert, presenting as educational or behavioural problems. Often, however, the hearing loss is first detected on routine screening examinations. Occasionally attention is drawn to it by frequent episodes of otalgia, which signify an acute episode of suppurative otitis media superadded to a middle ear effusion, and very occasionally presentation is with complications such as continuous otorrhoea secondary to perforation.

Treatment varies widely and is directed to the ears in the form of myringotomy and aspiration with or without insertion of a grommet; to the nose and sinuses by eradication of infection and control of allergy; and to the postnasal space and oropharynx in the form of adenoidectomy and tonsillectomy. It is removal of the adenoids and tonsils which is mainly responsible for the morbidity and mortality attached to the treatment of chronic otitis media with effusion. The main reasons postulated for adenoidectomy as a means of treatment and prevention of recurrence have centred on the size of the adenoids and their role as a focus for ascending eustachian tube infection. In addition, they are thought to alter nasopharyngeal pressure relations. The potential source of infection from the tonsils is similarly implicated. Removal of the tonsils, however, is often additionally advised with adenoidectomy on grounds which on their own merit might not prove valid for tonsillectomy.

Arguments for ${ }^{1-3}$ and against ${ }^{4-8}$ adenoidectomy and adenotonsillectomy for all types of disease of the middle ear have been discussed and reported at length in papers and symposia world wide. ${ }^{9-12}$ Nevertheless, given the large numbers of these operations performed for this condition, it is remarkable that so few studies have been carried out to substantiate their efficacy. Evidently the long held belief that adenoidectomy relieves recurrent acute suppurative otitis media has been extrapolated, as yet without convincing supportive evidence as grounds for the management of otitis media with effusion. The present study began prospectively in September 1979 with the specific object to evaluate randomly the effect of adenoidectomy and adeno- 
tonsillectomy together with no treatment on established otitis media with effusion unresponsive to medical treatment in children aged 2 to 11 years.

\section{Patients and methods}

The study was approved by the district ethical committee and was performed in two parts. A preliminary pilot study was undertaken to assess interobserver agreement and to validate my specificity $(75 \%)$, sensitivity $(90 \%)$, and accuracy of diagnosis of otitis media with effusion. That study has been reported. ${ }^{13} 14$

The definitive study was conducted during July 1979 to March 1982. At regular intervals throughout the period children suffering with bilateral otitis media with effusion were examined. There were 103 children aged between 2 and 11 years (mean $5 \cdot 25$ years), of whom 62 were boys and 41 girls. Diagnosis was confirmed by otoscopy using Siegle's pneumatic speculum together with compliance studies, tympanometry, acoustic reflex stimulation, and pure tone audiometry. On the first appointment the condition and trial were explained and an antihistamine-sympathomimetic amine mixture (Dimotapp elixir) in appropriate dosage for age prescribed until the second appointment six weeks later. Repeat examination and investigations were then performed to confirm the presence of bilateral otitis media with effusion. For the next six weeks no treatment was prescribed, and a final, identical review was made at 12 weeks.

If fluid in the middle ear was still present on both sides the trial was further explained and the child admitted to hospital within two weeks for operation. During this time a lateral cephalometric radiograph of the nasopharynx was taken. All the surgery was performed by me. Surgery to the tonsils and adenoids was allocated at random, as follows: adenotonsillectomy 34 cases; adenoidectomy 36; no surgery 33 . Additionally, in all cases on a randomly allocated basis unilateral myringotomy was performed. The middle ear fluid was aspirated and assessed for quantity and type. A Shepard Xomed grommet was inserted anteroinferiorly. The contralateral, unoperated ear was examined on this occasion with a Zeiss microscope using six times magnification to reconfirm clinically the presence of fluid in the middle ear but myringotomy was not performed. There was a similar distribution of each treatment group within the seasonal divisions of the year and there were no differences among the three groups in age, sex, and postnasal space airway measured on the lateral radiograph.

All 103 children entered the study. They were re-examined six weeks, three months, six months, nine months, and one year after surgery. I performed similar clinical examinations in all cases together with pure tone audiometry and impedance studies. The unoperated ear was assessed for fluid in the middle ear without prior examination of the pharynx or operation notes and a rate of improvement calculated for each follow up time based on the findings in the unoperated ear. The improvement rate represents the percentage of the unoperated ears in which fluid was no longer present as judged with a Siegle's pneumatic otoscope.

\section{Results}

Only one patient was lost to follow up (after three months). Some of the children failed to attend follow up appointments at the expected time; thus a comparison was made between the rate of resolution of otitis media with effusion observed at the precise time of follow up and an interpolated assessment at each selected follow up time based on the middle ear findings at the next appointment. Analysis by $\%^{2}$ test showed no difference in any of the cells between the observed and interpolated data, and therefore the larger numbers in the interpolated data were used for subsequent analysis (fig 1 ).

In the group treated by adenoidectomy alone the rate of improvement increased from $39 \%$ at six weeks to $56 \%$ at three months, $64 \%$ at six months, $58^{\circ},{ }_{0}$ at nine months, and $72 \%$ at one year. After adenotonsillectomy the rate changed from $59 \%$ at six weeks to $50 \%$ at three months, $59^{\circ} \%$ at six months, and $62^{\circ}$, at nine months and one year. In the no surgery, control group, however, the improvement rate increased from $16 \%$ at six weeks to $22 \%$ at three months, $26 \%$ at six months, $19^{\circ}$ at nine months, and $26^{\circ}$ at one year (fig 2 ). $\%^{2}$ analysis showed that compared with the no treatment group the effect of adenoidectomy alone was significant at three months $(p<0.05)$ and at six and nine months $(p<0.01)$ and one year $(p<0.001)$. Likewise, there was a significant effect after adenotonsillectomy at six weeks $(\mathrm{p}<0.001)$, three and six months $(\mathrm{p}<0.05)$, and at nine months and one

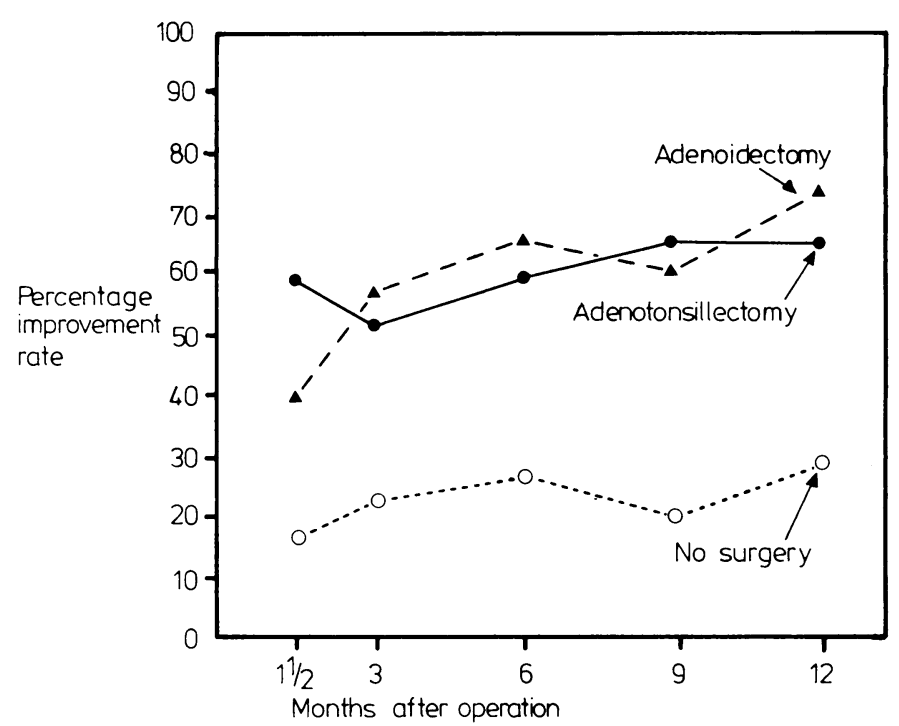

FIG 1-Comparison between observed and interpolated improvement rates. $\chi^{2}$ analysis showed no differences in any cells.

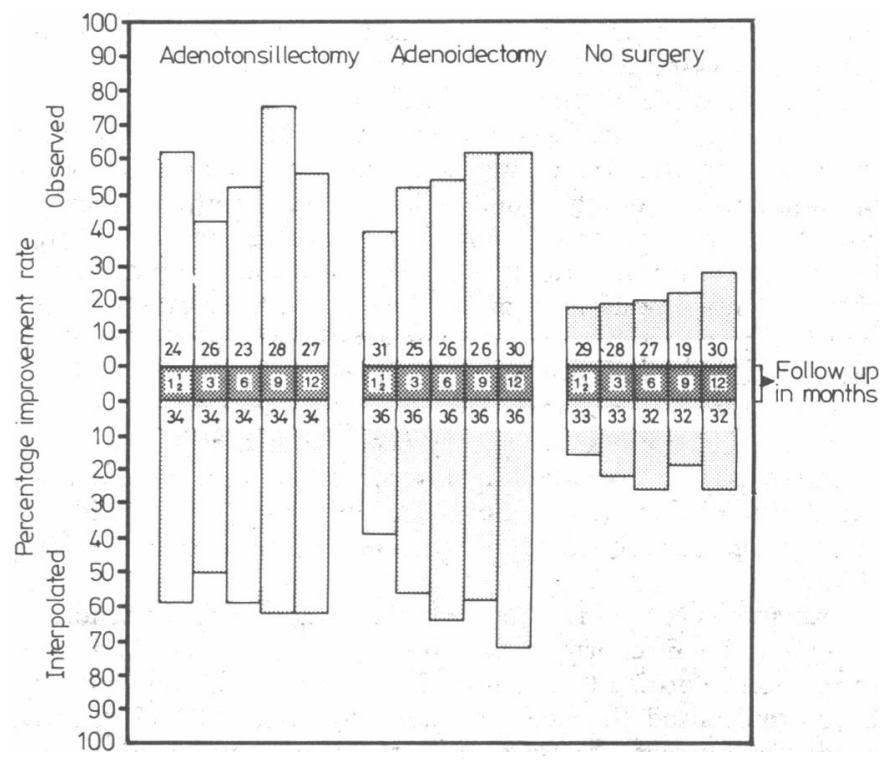

FIG 2-Percentage improvement rate of middle ear effusion after operation.

year $(p<0 \cdot 01)$. There was no significant difference between the adenoidectomy and adenotonsillectomy groups at any time after surgery.

\section{Discussion}

Tonsillectomy with adenoidectomy is less frequently recommended than adenoidectomy alone for otitis media with effusion, yet only two $^{415}$ of the six reported prospective studies investigated adenoidectomy in isolation from the combined operation for the relief of middle ear disease. Moreover, these studies assessed the overall effect of surgery in relieving various aural and upper respiratory tract signs and symptoms and none specifically investigated the effect of the procedures on otitis media with effusion as a properly controlled randomised prospective study. Sade found no improvement in otitis media with effusion after adenoidectomy and insertion of a grommet compared with insertion of a grommet alone ${ }^{6}$ and similar results were reported in a small study by Fiellau-Nikolajsen et al. ${ }^{16} \mathrm{~A}$ retrospective study by Marshak and Ben Neriah ${ }^{5}$ showed a statistically nonsignificant $(p<0.3)$ improvement rate in otitis media with 
effusion after adenoidectomy and myringotomy (74\%) compared with myringotomy alone $(59 \%)$. Roydhouse found no difference in cure rate of effusion after adenoidectomy, though there was a $9 \%$ greater relapse rate in a similar non-adenoidectomy group independent of adenoid size. ${ }^{7}$ After adenoidectomy recurrent acute suppurative otitis media has been seen to improve by some investigators, ${ }^{17-19}$ though others ${ }^{420}$ have found no improvement.

Little is known of the natural history of adenoid development and the growth of the nasopharynx. Jeans et al showed that growth of the soft tissue of the postnasal space outstrips growth of the nasopharynx from 3 to $5 \frac{1}{2}$ years of age with resultant reduction in the nasopharyngeal airway. ${ }^{21}$ Subsequently growth of the nasopharynx increases while the soft tissues remain relatively unchanged and thus the airway increases. Middle ear effusions have been detected where the adenoids either are not enlarged or have been removed. ${ }^{22}{ }^{23}$ Independently, Gerwat, ${ }^{24}$ Hibbert, ${ }^{25}$ and Maw et $a l^{26}$ found no correlation between size of the adenoids radiologically or volumetrically and the presence or absence of otitis media with effusion. By contrast, however, we have shown a significant reduction in the postnasal space airway $(\mathrm{p}<0.05)$ in children with the condition compared with age matched controls (A R Maw, W D Jeans, unpublished data). Bluestone et al in selected cases found improved function of the eustachian tube after adenoidectomy. ${ }^{27}$ They also found in some cases worsened tubal function with more frequent and more serious otitis media after adenoid removal. Birck and Mravec reported a $27 \%$ failure rate for adenoidectomy alone, particularly when allergy was coexistent. ${ }^{28}$

Other factors must be considered in relation to the evaluation of these operations for this condition. In many studies the material is not homogeneous ${ }^{20}$; some cases of effusion are bilateral, others unilateral, ${ }^{7}$ numerical problems arise, and often for ethical reasons patients with severe middle ear disease or gross adenoid enlargement are excluded. ${ }^{4}$ Paradise et $a l^{29}$ rightly stated that studies must assess the obvious variables of age, sex, degree of nasal obstruction, adenoid size, and allergy in addition to other factors such as seasonal variation and spontaneous improvement which may occur with time. ${ }^{30}$

There is also considerable interobserver and intraobserver variability in the assessment of these children, ${ }^{1314}$ and validation of investigators' accuracy of clinical diagnosis must be considered. ${ }^{*}$

Statements recommending virtual abandonment of adenoidectomy have been reported ${ }^{30}$ but still appear to be unsubstantiated in relation to otitis media with effusion. Almost all other studies have emphasised the need for carefully controlled prospective randomised trials to assess the place of adenoidectomy and tonsillectomy for otitis media with effusion. The work presented here is the first such study to be reported. It suggests that adenoidectomy has a significant therapeutic effect for up to 12 months in resolving the effusion in $36-46 \%$ of cases of established otitis media with effusion resistant to medical treatment. Moreover the effect is independent of age, sex, size of the adenoids, and the influence of any seasonal variation on the condition (A R Maw, unpublished data). It further suggests that combination of tonsillectomy with adenoidectomy does not confer any additional therapeutic benefit for this condition. Finally, it shows that without treatment $26 \%$ of cases resolve spontaneously during this time.

I am indebted to Professor John Colley and Dr Anthony Hughes, of the department of community health, University of Bristol, and to Dr David Bainton, of the Bristol Health District, for their continued support and advice.

\section{References}

${ }^{1}$ Bateman GH. Secretory otitis media. F Laryngol Otol 1959;71:261-76.

2 Gottschalk GH. Serous otitis. A conservative approach to treatment. Arch Otolaryngol 1972;96:110-2.

${ }^{3}$ Potsic WP. The role of adenoidectomy in secretory otitis media. In : Snow JB, ed. Controversy in otolaryngology. Philadelphia: W B Saunders, 1980:154-9.

4 Rynnel-Dagoo B, Ahlbom A, Schiratzki H. Effects of adenoidectomy: a controlled two-year follow-up. Ann Otol Rhinol Laryngol 1978;87:272-8.

${ }^{5}$ Marshak G, Ben Neriah $Z$. Adenoidectomy versus tympanotomy in chronic secretory otitis media. Ann Otol Rhinol Laryngol 1980;89, suppl 68: 316-8.

${ }^{6}$ Sade J. Secretory otitis media and its sequelae. New York: Churchill Livingstone, 1979.

${ }^{7}$ Roydhouse N. Adenoidectomy for otitis media with mucoid effusion Ann Otol Rhinol Laryngol 1980;89, suppl 68:312-5.

${ }^{8}$ Stool SE. Myringotomies and tympanostomy tubes are sufficient. In: Snow JB, ed. Controversy in otolaryngology. Philadelphia: W B Saunders, $1980: 150$.

${ }^{9}$ Lim DJ, Bluestone CD, Saunders WH, Senturia BH. Recent advances in middle ear effusions. Ann Otol Rhinol Laryngol 1976;85, suppl 125:1299.

${ }^{10}$ Senturia BH, Bluestone CD, Lim DJ, Saunders WH. Recent advances in otitis media with effusion. Ann Otol Rhinol Laryngol $1980 ; 89$, suppl 68: 1-362.

11 Paradise JL. Paediatrician's view of middle ear effusions: more questions than answers. Ann Otol Rhinol Laryngol 1976;85, suppl 25:20-4.

12. Snow JB. Role of tonsillectomy and adenoidectomy in the management of children with middle ear effusion. Ann Otol Rhinol Laryngol 1980;89, suppl 68:43-6.

${ }^{13}$ Maw AR. Preliminary findings for interobserver variability in children with middle ear effusions and adenoids. Clin Otolaryngol 1979;4:149.

${ }^{14}$ Maw AR, Jeans WD, Fernando DCJ. Interobserver variability in the clinical and radiological assessment of adenoid size and the correlation with adenoid volume. Clin Otolaryngol 1981;6:317-22.

${ }^{15}$ McKee WJE. A controlled study of the effects of tonsillectomy and adenoidectomy in children. British fournal of Preventive and Social Medicine 1963;17:49-69.

${ }^{16}$ Fiellau-Nikolajsen M, Falbe-Hansen J, Knudstrup P. Adenoidectomy for middle ear disorders: a randomised controlled trial. Clin Otolaryngol $1980 ; \mathbf{5}: 323-7$.

17 Kaiser AD. Results of tonsillectomy: a comparative study of 2200 tonsillectomized children with an equal number of controls, 3 and 10 years after operation. FAMA 1930;95:837-42.

${ }^{18}$ McKee WJE. A controlled study of the effects of tonsillectomy and adenoidectomy in children. British fournal of Preventive and Social Medicine 1963;17:133-40.

19 Roydhouse N. A controlled study of adeno-tonsillectomy. Arch Otolaryngol 1970;92:611-6.

${ }^{20}$ Mawson SR, Adlington P, Evans A. A controlled evaluation of adenotonsillectomy in children. $\mathcal{F}$ Laryngol Otol $1967 ; 81: 777-90$

21 Jeans WD, Fernando DCJ, Maw AR, Leighton BC. A longitudinal study of the growth of the nasopharynx and its contents in normal children. Br f Radiol 1981;54:117-21.

$2: 2$ Dawes JDK. The aetiology and sequelae of exudative otitis media. $\mathfrak{f}$ Laryngol Otol 1970;84:583-610.

${ }^{23}$ Mawson SR, Brennand J. Long term follow-up of 129 glue ears. Proc $R$ Soc Med 1969;62:460-3.

24 Gerwat J. The structure and function of the nasopharyngeal lymphoid tissue with special reference to aetiology of secretory otitis media. 7 Laryngol Otol 1975;89:169-74.

${ }^{25}$ Hibbert $\mathrm{J}$. The role of enlarged adenoids in the aetiology of serous otitis media. Clin Otolaryngol 1982; 7:253-6.

26 Maw AR, Jeans WD, Cable HR. Adenoidectomy: a prospective study to show clinical and radiological changes two years after operation. f Laryngol Otol 1983;97:511-8.

27 Bluestone CD, Cantekin EE, Beery QC. Certain effects of adenoidectomy on eustachian tube ventilatory function. Laryngoscope $1975 ; \mathbf{8 5}: 113-27$.

28 Birck HD, Mravec JJ. Myringostomy for middle ear effusions. Results of a two year study. Ann Otol Rhinol Laryngol 1976;85, suppl 25:263-7.

29 Paradise JC, Bluestone CD, Rogers KD, Taylor FH. Efficacy of adenoidectomy in recurrent otitis media: historical overview and preliminary results from a randomised controlled trial. Ann Otol Rhinol Laryngol $1980 ; 89$, suppl $68: 319-21$.

30 Stell PM. Adenoidectomy. Clin Otolaryngol $1981 ; 6: 1-3$.

(Accepted 13 September 1983) 